\title{
Contrast-Induced Encephalopathy after Primary Percutaneous Coronary Angioplasty Mimicking a Subarachnoid Hemorrhage
}

\author{
Oktay Senöz, Sadik Volkan Emren'1, Ahmet Erseçgin, Zeynep Yapan Emren, Yasemin Bozkaya \\ Department of Cardiology, Çiğli State Hospital, 'Department of Cardiology, Katip Çelebi University, Izmir, Turkey \\ ORCID: \\ Oktay Senöz: https://orcid.org/0000-0002-3847-7598 \\ Sadik Volkan Emren: https://orcid.org/0000-0002-7652-1123 \\ Ahmet Erseçgin: https://orcid.org/0000-0002-1687-9481 \\ Zeynep Yapan Emren: https://orcid.org/0000-0002-5508-9474 \\ Yasemin Bozkaya: https://orcid.org/0000-0002-2553-5701
}

\section{Abstract}

Contrast-induced encephalopathy (CIE) is a rare temporary phenomenon after intravenous injection of contrast media. The prognosis is generally good. Neurological symptoms develop within hours and resolve spontaneously over days. Global syndromes such as confusion can also be seen with cortical and subcortical deficits. There is a good correlation between the volume of contrast extravasation and clinical picture. In addition, this extravasation can be confused with intracranial hemorrhage in the early stage with imaging. In this case, we presented a 62-year-old male patient who developed CIE after coronary angioplasty mimicking subarachnoid hemorrhage and spontaneously recovered on the $2^{\text {nd }}$ day of the event.

Keywords: Angiography, contrast-induced encephalopathy, coronary intervention, encephalopathy, subarachnoid hemorrhage

\section{INTRODUCTION}

Encephalopathy caused by contrast agents is a rare complication of percutaneous coronary interventions. ${ }^{[1]}$ This phenomenon was first described in 1970 as transient cortical blindness after coronary angiography. ${ }^{[2]}$ The incidence of contrast-induced encephalopathy (CIE) ranges between $0.3 \%$ and $1.0 \%$ but can increase to $4 \%$ when hyperosmolar iodinated contrast agents used. $^{[3]}$ This rare complication of coronary intervention is barely recognized by the cardiologist. Herein, this report describes an unusual case of transient encephalopathy following coronary angioplasty mimicking subarachnoid hemorrhage (SAH) both clinically and radiologically.

\section{Case Report}

A 62-year-old male patient admitted to the emergency room with complaints of extreme weakness and near syncope. He was conscious and had no chest pain. He had a history of

Received: 02-07-2020 Revised: 26-07-2020 Accepted: 13-08-2020

Published Online: 27-11-2020

\begin{tabular}{|l|l|}
\hline \multicolumn{3}{|c|}{ Access this article online } \\
\hline Quick Response Code: & Website: \\
& \\
http://www.ijcva.com
\end{tabular}

diabetes mellitus and smoking. On physical examination, his blood pressure was $85 / 50 \mathrm{mmHg}$ and pulse rate was 48 / min. Blood sugar was $208 \mathrm{mg} / \mathrm{dl}$. Electrocardiogram (ECG) showed sinus bradycardia with $2 \mathrm{~mm}$ ST-segment elevation in the inferior leads. Bedsides echocardiography demonstrated $40 \%$ left ventricular ejection fraction with inferior and posterior wall hypokinesia. The patient was rushed to the catheter laboratory with the diagnosis of acute inferior myocardial infarction. Coronary angiography from the right femoral artery showed an acute mid total occlusion in the right coronary artery (RCA) [Figure 1a] and noncritical plaques in the left anterior descending and circumflex artery. The patient was administrated $300 \mathrm{mg}$ of acetylsalicylic acid and $600 \mathrm{mg}$

\section{Address for correspondence: Dr. Sadik Volkan Emren, \\ Department of Cardiology, School of Medicine, Katip Celebi University, Izmir 35160, Turkey.} E-mail: vemren@hotmail.com

This is an open access journal, and articles are distributed under the terms of the Creative Commons Attribution-NonCommercial-ShareAlike 4.0 License, which allows others to remix, tweak, and build upon the work non-commercially, as long as appropriate credit is given and the new creations are licensed under the identical terms.

For reprints contact: WKHLRPMedknow_reprints@wolterskluwer.com

How to cite this article: Senöz O, Emren SV, Erseçgin A, Emren ZY, Bozkaya Y. Contrast-induced encephalopathy after primary percutaneous coronary angioplasty mimicking a subarachnoid hemorrhage. Int $\mathrm{J}$ Cardiovasc Acad 2020;6:183-5. 
loading dose of clopidogrel. A total of $7500 \mathrm{U}$ of heparin was administered during angioplasty. After pre dilatation with 2.0 $\mathrm{mm} \times 15 \mathrm{~mm}$ balloon, $2.25 \mathrm{~mm} \times 28 \mathrm{~mm}$ and $2.25 \mathrm{~mm} \times 15$ mm drug-eluting stents (X1ence pro-Abbott) were implanted into the RCA mid-region. The operation was successfully terminated with thrombolysis in myocardial infarction-3 RCA flow [Figure 1b]. The entire procedure took approximately $90 \mathrm{~min}$ and required a total amount of $250 \mathrm{ml}$ low osmolar nonionic contrast media (Iohexol). Shortly after the procedure, the patient suffered blindness and impaired consciousness while he was still in the catheter laboratory. Brain computed tomography (CT) and magnetic resonance imaging (MRI) was performed to rule out an acute cerebrovascular event. When the patient was transferred to the intensive care unit, right hemiparesis was occurred. Brain CT showed diffuse cortical hypoattenuation in the left hemisphere which was liked to be seen in SAH [Figure 2a and b]. Also, cranial CT showed edema with effacement of sulci of the left cerebral hemisphere. MRI showed no ischemic changes [Figure 3]. After consulting the patient with neurology and neurosurgery, widespread SAH was considered due to the clinical picture and brain CT findings. The neurosurgical operation was not planned. Medical treatment included intravenous mannitol infusion, piecemeal dose of furosemide, and intravenous dexamethasone in order to treat brain edema. Antiaggregants were stopped. The patient was followed under close monitoring in the coronary intensive care unit. On the $2^{\text {nd }}$ day, the patient's neurological deficits began to regress clinically by

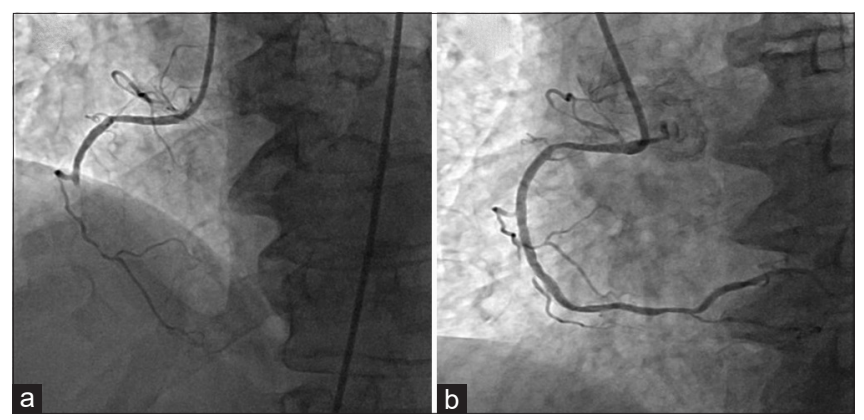

Figure 1: Coronary angiogram showed an acute total occlusion of right coronary artery (a). Complete right coronary artery restoration flow after coronary angioplasty (b)
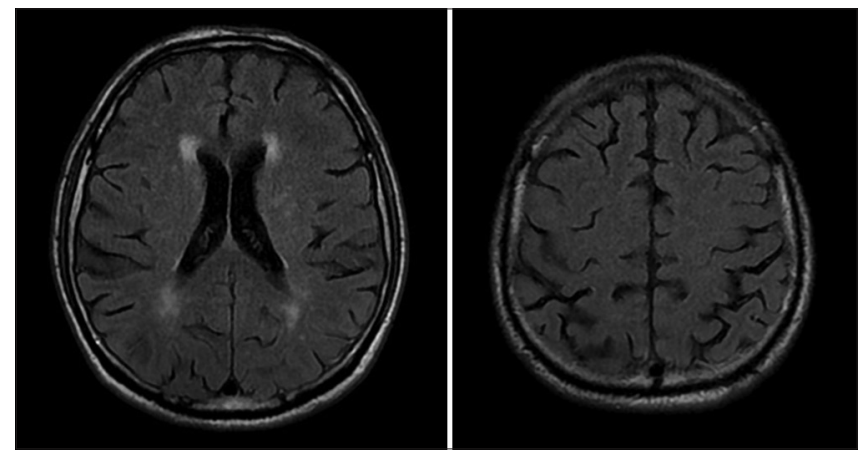

Figure 3: Cranial magnetic resonance imaging ruled out acute ischemic changes in brain the improvement of confusion and blindness and significantly decreasing of right hemiparesis. On the $2^{\text {nd }}$ day after the procedure, control brain CT showed significant improvement as well [Figures 4, Figure 3a and b]. The patient was deemed to had no SAH but CIE due to the rapid recovery of clinical and radiological neurological findings without obvious treatment. Antiaggregant treatments were restarted. During this period, the patient did not have chest pain and no ischemic change in ECG. On the $4^{\text {th }}$ day, the right hemiparesis of the patient was completely recovered. He was mobilized in the service. On the $6^{\text {th }}$ day, the patient was discharged uneventfully under dual antiplatelet therapy.

\section{Discussion}

CIE is a very rare complication of both diagnostic coronary angiography and percutaneous coronary interventions. It is most commonly seen after cerebral angiography and carotid angioplasty [Figure 4]. ${ }^{[4]}$ For coronary procedures, large contrast volumes or end-stage renal failure are the main factors for CIE. ${ }^{[5,6]}$ The incidence of CIE ranges between $0.3 \%$ and $1.0 \%$, although it can increase $4 \%$ when hyperosmolar iodinated contrast agents are used. Nonionic and hyperosmolar agents further increase the risk of CIE. ${ }^{[3,5]}$ Transient ischemic attack (TIA) tends to increase the permeability of the bloodbrain barrier. Therefore, the history of TIA is a predisposing factor for CIE. Chronic
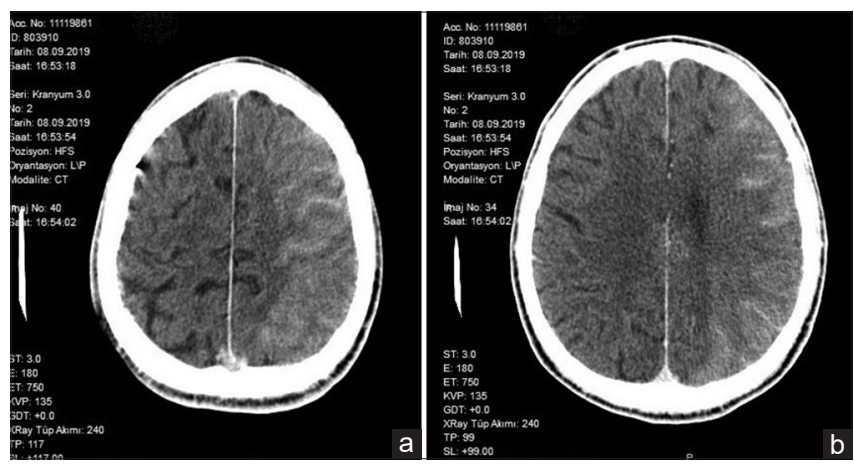

Figure 2: Immediate postprocedural computed tomography scan of brain without contrast showing diffuse cortical enhancement over left hemisphere $(a$ and $b)$
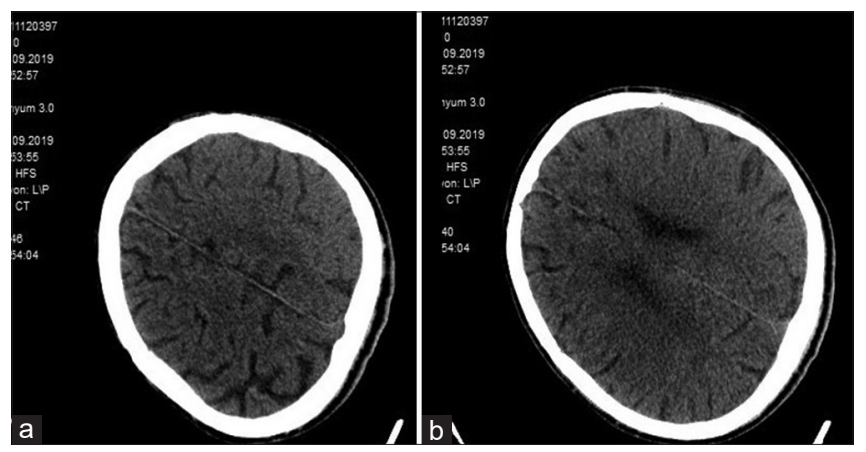

Figure 4: Computed tomography scan of brain without contrast 2 days later after coronary intervention showing a significant regression of diffuse cortical enhancement ( $a$ and $b$ ) 
hypertension and impaired cerebral autoregulation may be the other risk factors for contrast extravasation. ${ }^{[5]}$

Clinical presentations of CIE include localized cortical and subcortical deficits (e.g., hemiparesis, hemianopia, cortical blindness, speech changes, and parkinsonism) and global cortical syndromes, such as confusion, seizure, and coma..$^{[5-7]}$ Patient's neurological status usually develops within hours of contrast medium exposure and it is expected to recover over a period of days. The prognosis is generally good even in severe cases, including coma. ${ }^{[7]}$ In our case despite using low-osmolar nonionic contrast media (Iohexol) patient still suffered encephalopathy.

Although the precise mechanism of injury is not well understood, it has been postulated that a combination of chemotoxic effects of contrast hyperosmolality and direct neurotoxicity of the contrast agent played a considerable role. The occipital cortex is one of the regions having higher permeability of the bloodbrain barrier. Therefore neurological deficits, such as cortical blindness and ophthalmoplegia are common manifestation. ${ }^{[8]}$

Clinical symptoms can be confused with SAH and massive cerebral infarction. The correct diagnosis of CIE allows us to avoid the risks associated with the erroneous treatment of cerebrovascular ischemia or SAH. ${ }^{[9]}$ Imaging is important to confirm the diagnosis and to rule out thromboembolic and hemorrhagic complications. Brain CT without contrast plays the most important role in diagnosis showing diffuse cortical hyperattenuation similar to SAH There is a good correlation between the cerebral regions exposed to extravasated contrast and the patient's neurological deficits. ${ }^{[5-7]}$ Characteristic of high-intensity signals measuring 80-60 Hounsfield units (blood is $40-60 \mathrm{HU})$, can be considered pathognomonic and can help to distinguish this diagnosis from a major stroke or SAH in $\mathrm{CT} .{ }^{[7]}$

Since there is no specific treatment for CIE prevention is utmost important. To avoid CIE, it may be beneficial to start fluid and reduce the amount of contrast in all patients scheduled for interventional treatment neurological status of most patients can be improved with supportive care alone including adequate hydration with intravenous crystalloids and anticonvulsants for seizures. In a few cases, patients were treated with intravenous steroids and mannitol with no adverse consequences. ${ }^{[3]}$

\section{Conclusion}

Although CIE is rarely seen cardiac catheter laboratory. It should be kept in mind in patients suffered neurological symptoms after coronary procedures using contrast agents. As the CIE can be confused with other neurological complications such as stroke and SAH, the clinical course of patient and imaging methods can be helpful in diagnosing and differentiating CIE.

\section{Declaration of patient consent}

The authors certify that they have obtained all appropriate patient consent forms. In the form the patient(s) has/have given his/her/their consent for his/her/their images and other clinical information to be reported in the journal. The patients understand that their names and initials will not be published and due efforts will be made to conceal their identity, but anonymity cannot be guaranteed.

\section{Financial support and sponsorship}

Nil.

\section{Conflicts of interest}

There are no conflicts of interest.

\section{RefEREnCES}

1. Kocabay G, Karabay CY. Iopromide-induced encephalopathy following coronary angioplasty. Perfusion 2011;26:67-70.

2. Fischer-Williams M, Gottschalk PG, Browell JN. Transient cortical blindness. An unusual complication of coronary angiography. Neurology 1970;20:353-5.

3. Potsi S, Chourmouzi D, Moumtzouoglou A, Nikiforaki A, Gkouvas K, Drevelegas A. Transient contrast encephalopathy after carotid angiography mimicking diffuse subarachnoid haemorrhage. Neurol Sci 2012;33:445-8.

4. Wishart DL. Complications in vertebral angiography as compared to non-vertebral cerebral angiography in 447 studies. Am J Roentgenol Radium Ther Nucl Med 1971;113:527-37.

5. Guimaraens L, Vivas E, Fonnegra A, Sola T, Soler L, Balaguer E, et al. Transient encephalopathy from angiographic contrast: A rare complication in neurointerventional procedures. Cardiovasc Intervent Radiol 2010;33:383-8.

6. May EF, Ling GS, Geyer CA, Jabbari B. Contrast agent overdose causing brain retention of contrast, seizures and parkinsonism. Neurology 1993;43:836-8.

7. Yu J, Dangas G. New insights into the risk factors of contrast-induced encephalopathy. J Endovasc Ther 2011;18:545-6.

8. Kahyaoğlu M, Ağca M, Çakmak EÖ, Geçmen Ç, İzgi İA. Contrast-induced encephalopathy after percutaneous peripheral intervention. Turk Kardiyol Dern Ars 2018;46:140-2.

9. Terlecki M, Wojciechowska W, Rajzer M, Jurczyszyn A, Bazan-Socha S, Bryniarski L, et al. Transient cortical blindness after coronary artery angiography. Postepy Kardiol Interwencyjnej 2013;9:105-8. 